\title{
Chapter 4 \\ What Richardson Got Right (and Wrong) About Arms Races and War
}

\author{
Paul F. Diehl
}

\begin{abstract}
This chapter considers Richardson's classic arms race model and his book Arms and Insecurity in relation to the association between arms races and war. The analysis begins with a short review of the academic debates and empirical research about arms races and war. This is a prelude to an examination of the dynamics of arms races as they are specified by Richardson in his book and in his arms race model. Following is an evaluation of the specific claims about arms races and war derived from the model as well as Richardson's own empirical analyses about the connection between the two phenomena. Although in light of subsequent research, a number of Richardson's arguments seem misguided or inaccurate, other insights were validated by later studies or remain understudied but worthy of future research.
\end{abstract}

Lewis Fry Richardson was one of the pioneers of the quantitative study of war (along with Quincy Wright and Pitirim Sorokin), and his work has stood the test of time and continues to influence scholars. Richardson is most famous for his equations that model the dynamics of arms races. Indeed, these dominate much of his book Arms and Insecurity (Richardson, 1960). Nevertheless, it is easy to forget that the subtitle of the work is A Mathematical Study of the Causes and Origins of War. Thus, there was a clear belief for Richardson that arms races, although not all of them, were associated with the outbreak of war. Periodically throughout the book, he refers to arms races and war, and includes a series of case studies of arms races in the 19th and first half of the 20th century.

How much of Richardson's assessment of arms races and war have turned out to be correct (or not)? Since the publication of his work, there has been an extensive set of research on the connection of these two phenomena, and we now have an empirical basis for reflecting on Richardson's insights at the dawn of systematic, empirical work on war. The focus of this chapter is to present Richardson's models and claims as they related to arms races and war, and then evaluate them in light of subsequent research. 


\subsection{The Arms Race-War Debate}

A debate over the dangers (or lack thereof) of arms races for the onset of war have been among the most enduring in international relations scholarship. Although Huntington (1958) first raised the issue, controversy did not ensue until the publication of Wallace's (1979) article more than two decades later. This article received extensive attention in the scholarly and policymaking communities not the least for its relevance to the nuclear disarmament campaign at the time and its provocative findings. Wallace essentially argued that arms races were extremely dangerous and had strong likelihood of leading to war between the participants. The study was severely flawed and not replicable, and consequently it attracted a fair amount of criticism for its methodology and case selection (e.g., Houweling \& Siccama, 1981; Diehl, 1983).

The original Wallace article had the benefit of raising the issue of the arms race-war connection, but also the unfortunate side effect of focusing the debate on research design concerns rather than theoretical explanations. The arms race-war debate has settled down somewhat with a consensus emerging that the competitions are dangerous in some contexts and under some circumstances (see Sample, 2012 for an overview), although whether they are causal or merely symptomatic is still contentious (Rider, Findley \& Diehl, 2011). The work of Richardson (1960) was often perfunctorily cited in these debates, but rarely if ever were his specific ideas about the arms races and war discussed or incorporated in the analyses. The discussion below is designed to return to Richardson's original formulation to correct that deficiency and determine whether the literature has missed anything that would be of value to future research.

\subsection{Richardson on Arms Races and War}

For a work that is purportedly about the origins of war, Arms and Insecurity has remarkably little to say directly about the conditions for the outbreak of war, especially as they relate to arms races. Indeed, the book is largely dedicated to modelling the dynamics of arms races, which is also the focus of Smith (2020, in this volume). The famous differential equations for arms races and their variations take up most of the work. Not surprisingly then, most of the research that has been influenced by (and cites) Richardson's work has been dedicated to arms race models, even as those models have some notable limitations (see Zinnes, 1980). To the extent that empirical analyses are found in his work, they are focused more on fitting the models to data on military expenditures than on linking arms races to war in a causal process. Case studies of World Wars I and II are sprinkled throughout the book, and these are no doubt chosen because they were contemporary examples for Richardson, but their magnitude also commanded attention. 
Trawling through the work, there are numerous insights about arms races and war. Some of these come from the differential equations that reviewed by Smith (2020). Nevertheless, more are found in the narrative and case studies that make up the rest of the book. In sorting these out, I have roughly divided these into three categories below. The first set covers the dynamics of arms races as they relate to the study of arms races and war. The second deal with specific claims about the connection between the two phenomena. Finally, there are empirical analyses, primary and secondary, reported by Richardson.

\subsubsection{The Dynamics of Arms Races and Their Implications for the Study of War}

Richardson was prescient in a number of ways on how scholars should look at arms races and the conditions for war more broadly. Several of his ideas portend later, and more precise, formulations in the conflict studies literature. A number of the insights specifically about arms races remain salient and somewhat unexplored today. Richardson was also very concerned about data quality and measurement, specifically the reliability and comparability of the data were as well as the match between concepts and indicators. Although this chapter does not cover these issues, the reader is encouraged to examine and emulate the good practices followed by Richardson.

A repeated theme in the narrative is a concern for considering the power distribution of the states involved and whether each had a status quo versus revisionist orientation (Richardson, 1960: 26, see also 13,35). This is now evident in light of empirical research on war over the last 70 years, but at the time (contemporary to Morgenthau and realism), this was an important formulation. With respect to arms races, Richardson (1960: 21) claims that the defense coefficient is proportional to the size of the state, indicating that extant capabilities and resources matter. There is also the related concern that defense burdens are important, both for the pace of the arms race and for the timing of the outbreak of war (more on this below).

Despite what might now seem as obvious considerations, much of the arms race-war empirical work ignores these considerations, even as these are centerpieces of general theories of war (for a general review of the literature, see Sample, 2012). For example, there is a tendency to look at the rates of increase in military spending for each side in an arms race without consideration to how the power distribution affects those rates, or vice-versa. There is also little consideration given to how defense burdens constrain (part of the fatigue factor in Richardson, 1960: 13), or facilitate arms increases and their relation to the outbreak of war (an exception is Diehl, 1985). Such failures have led much of the arms race-war literature to be delinked from the rest of the empirical conflict literature on power transitions and other theoretical models. 
In a related fashion, Richardson makes reference to what we call 'rivalries' and how these influence arms races. The rivalry element suggests that we look at arms races in that context, a point raised in some recent debates about arms races and war (Rider, Findley \& Diehl, 2011; Sample, 2012). Doing so brings in the issues of relative power distribution and status quo-revisionist considerations noted above. Rivalry can also be one element of what Richardson calls 'grievances', one of the drivers of arms increases in his model; grievances is a polyglot category encompassing all factors independent of the opponent's expenditures in driving one's own arms increases (Richardson, 1960: 16). This comports with rivalry research that finds that the 'pull of the past' and prior rivalry interactions influence current conflict behavior (Goertz, Jones \& Diehl, 2005).

Richardson also captures the elements of what we now refer to as the 'security dilemma' (Jervis, 1978a, b) when he states that '... governments which develop their armaments cannot expect their professions of peace intentions to be believed ...' (Richardson, 1960: 65). Mistrust and hostility coming from threat perception is the theoretical basis for scholarly arguments that posit that arms races increase the likelihood of war (Sample, 2012). Arms races increase the perception of threat, and indeed it is the reactivity of the Richardson model that captures this, and this undermines the ability and willingness of states to resolve their disagreements peacefully.

Another aspect of arms race dynamics put forward by Richardson that could influence its connection to war is the existence of cooperation between arming states. This could mitigate the impact of arms races (Richardson, 1960: 29ff, Chs VIII, XX). Trade is treated as the indicator of cooperation for Richardson's purposes, but his point is broader than about the effect of this particular variable (Richardson, 1960: 32). Although there is a large and vibrant literature on the impact of trade and interdependence on war (Schneider, 2010), countervailing factors are not usually a part of the arms race-war literature.

Richardson offered several propositions that subsequently have or should have influenced the arms race-war literature, but there are other aspects of his dynamics of arms races that are suspect for understanding their connection to war. One is how one treats aligned states in an arms race context. Richardson assumes that all allies are part of the arms race dynamics on the given side; in practice, this means aggregating their military expenditures (Richardson, 1960: 31f). The justification for this is atheoretical and especially weak: '.. an important advantage to be gained by lumping together the statistics from as many nations as can be reasonably treated; for this agglomeration smooths the statistics and moves them further away from the domain of free will toward the domain of exact science' (Richardson, 1960: 80). He does back away from this later in the book when he raises the concern that one must pay attention to whom is targeted by the increases (Richardson, 1960: 159ff). The arms race-war literature has struggled with the problem of disaggregating war initiations (e.g., World War I) into dyads (see Wallace, 1979; Diehl, 1983), but has not generally aggregated alliance spending when calculating arms race scores. To do so masks individual state decisions for spending and war, implying that allies act as one entity and are 
perceived as such by enemies; nevertheless, we know that alliances are not all reliable (Leeds, 2003). Richardson's claim that after alliances the defense coefficients of allies vis-à-vis each other go to zero (Richardson, 1960: 170) seems more of an unwarranted assumption than a reflection of cases in which allies are also rivals with each other (e.g., Greece-Turkey) or fight wars against one another (Ray, 1990).

\subsubsection{More Specific Claims About Arms Races and War}

At various junctures in the book, Richardson makes references to arms races and war, albeit sometimes cryptically and others in ways that make it difficult to discern when arms races are dangerous and when they are more benign. Indicative of this is late in the book when he refers to have presented a 'theory of the stability or instability of peace' (Richardson, 1960: 147). One might guess that he is referring to negative peace, or the absence of war, but this is perhaps the first time Richardson makes explicit reference to the conditions for peace.

The most direct discussion of arms races and war comes in $\mathrm{Ch} \mathrm{V}$ in the subsection labelled 'Bankruptcy or War?' (Richardson, 1960: 61f). Starting with his famous equations, Richardson notes that $x$ and $y$ (the increases in defense expenditures) would go to positive infinity, as the action-reaction process was deterministic. He notes that a critic (Professor Piaggio) argued that 'An infinite cost of armaments is interpreted as denoting war, though it might have seemed more natural to have taken it as bankruptcy' (quoted in Richardson, 1960: 61). In a strict interpretation, neither the bankruptcy nor war is a plausible outcome from the arms race process as specified. As Richardson correctly notes, there is no known case of a state going bankrupt from an arms race, a statement as true when written as today. More significant is the imprecision as to what point war becomes the outcome of the arms race. Is it only when one or both states have exhausted all their resources in pursuit of building armaments? This seems absurd and equally without empirical referents.

Richardson's other responses to his critic offer somewhat better, albeit still flawed, clues as to when arms races lead to war (Richardson, 1960: 61-62). Least compelling is the idea that '.. diplomatic relations become, during the tacit mutual threats of an arms race, such a strain that the outbreak of war is felt as a relief' (Richardson, 1960: 61). This suggests a threshold for war short of resource exhaustion, but it is not clear when that might be or how it might vary across states and their leadership. Nevertheless, the crippling effects of resources devoted to military spending is the basis for Huntington's (1958) assertion that quantitative arms races are destabilizing and prone to war, especially as they lengthen; this is consistent, although no more precise in terms of timing, with Richardson's formulations.

More useful is the implication that arms races have a strong psychological impact on decision makers, and this maps well with Richardson's emphasis on threats and the aforementioned security dilemma argument. Indeed, Richardson 
argues that the $x$ and $y$ variables in the structural equations of arms races conceptually represent threat and that military expenditures are merely imperfect measures of threat (Richardson, 1960: 61). The psychological element is also derived and discussed in more detail in Richardson's other work on 'war moods' (Richardson, 1948). Threat perception is a central element of most explanations for the arms race-war connection (Sample, 2012). Nevertheless, the psychology of arms races and their connection to war are often assumed or discussed, but not frequently tested in experimental or empirical studies (see Jervis, 1978b; Kydd, 2000).

Most promising is Richardson's response to his critic that $x$ is not merely a term representing threat, but 'threats minus co-operation' (Richardson, 1960: 61, quote marks in original). Often forgotten in applications of his model, this is a significant qualification to models that seemed to portend runaway arms races. This suggests that there can be substantial limits on arms races stemming from cooperation between the competitors. As noted above, trade is used as a surrogate indicator for such cooperation. Rivalry is treated as a possible accelerator for arms races. Similarly, Senese \& Vasquez (2008) list arms races as one of the 'steps to war' along with other war-promoting conditions. In both cases, however, scholars add other factors that make the escalatory effects of arms races worse rather than taking the lead of Richardson and incorporating factors that mitigate those impacts.

The above suggestion that arms races are not deterministic is segue to some of Richardson's other theorizing about their connection to war. Some of this is inductively derived from an analysis of cases (see next section). De facto, he makes a distinction between 'stable' and 'unstable' arms races, with the latter to be regarded as dangerous (Richardson, 1960: 74-76). Richardson makes an important distinction between the 'velocity' and the 'acceleration' of an arms race (Richardson, 1960: 63). The former refers to the speed of the race, and can be signified by the yearly rate of arms increases. The latter is the degree to which that speed increases over time. Roughly, unstable arms races, and therefore ones likely to end in war, are those in which the acceleration rate is increasing. In contrast, stable arms races are those that show a slowing of the rate of increase and ones that might promote a balance of power between the two enemies. Contrary to what Richardson suggests about the importance of acceleration relative to velocity, more contemporary scholars focus on yearly increases in military expenditures - speed and do not pay attention to whether this is increasing over time or not. This gap in the literature suggests possible future lines of inquiry.

\subsubsection{Empirical Findings}

Although Richardson's work is more about mathematical modelling than empirical testing, he does present some findings specifically on the arms race-war connection. This is done by reference to his reading of historians' assessments, his own quantitative analyses, and a series of case studies. 
To his credit, Richardson was not an ahistorical modeler, but someone deeply steeped in actual cases with a good command of history. Accordingly, it is not surprising that he delved into the conclusions of historians as a way of framing his own investigations. Richardson notes that historians mention arms races for only 10 of 84 wars in the period 1820-1929; World War I is the most notable (Richardson, 1960: 70). He suggests that historians might have missed some arms races, and in any case they would not normally pay attention to statistics and in particular whether the acceleration was increasing or not (Richardson, 1960: 70); the latter is what he regards as a core component of dangerous arms races.

Richardson's own empirical analysis at the outset of the book suggests looking more carefully at different kinds of arms races (Richardson, 1960: 2ff). The domain of his examination is 15 countries in World War I. He examines the opposite of the si vis pacem, para bellum ('if you want peace, prepare for war') dictum. This is akin to the inverse of a deterrence argument, something that he later suggested might have the opposite effect: 'The evidence shows what was designed as a deterrent sometimes acted instead as an irritant' (Richardson, 1960: 55). He also looks at whether increased arms spending results in greater 'insurance' for the states involved, namely that it reduces the suffering should war break out. One of Richardson's dependent variable is total deaths (civilian and military) in the war. Thus, war onset and war severity for individual countries are muddled. He conducts several simple statistical tests between arms levels and outcomes (product moment correlations, Fisher's test) and finds no significant association between arms races and war, and with war suffering (Richardson, 1960: 8-11). Nevertheless, this initial exploration looks only at expenditures three years prior to a war (Richardson, 1960: 7), an unnecessary limitation that complicates the ability of the analyst to distinguish between spending in anticipation of war and spending that is causal in precipitating war; such a narrow window also is insufficient to detect acceleration (or lack thereof).

More detailed examinations are found later in the book, although again the focus is more on the dynamics of the arms races than their outcomes (Richardson, 1960: 7, Chs VI, VII). Examining some national interactions prior to World War I, Richardson considers how arms races produced (or not) stable equilibriums, namely balances of power. These get closer to testing his arguments about acceleration and (un)stable arms races. Yet the results are decidedly mixed, with Richardson expressing equivocation or ignorance as to whether arms races produce clear effects, with some cases fitting the argument and others not (see conclusions in Richardson, 1960: 7 and 76). Moving to the European context from 1908-14, there is greater consideration given to a longer time series for arms race data, although the author does aggregate spending within the two major alliances. It is difficult to discern precise conclusions about war, but the movement away from a point of balance and the positive instability coefficients suggest an arms race of a dangerous type. This is not surprising in that there is consensus even among arms race-war skeptics that World War I was preceded by an arms race. Richardson does conclude that there was equilibrium among European powers in 1907 and 1908, and had the arms race been muted by a small amount, the First World War might have been 
avoided (Richardson, 1960: 109-110). This counter-factual claim is one that is unlikely to be accepted by subsequent historians and international relations scholars.

More interesting is the examination of the relative impact of cooperation (measured as trade) vis-à-vis arms races. Trade between rival alliance blocs was increasing prior to World War I. There was also a trade agreement between Russia and Germany prior to World War II. Thus, the pacifying effects of trade are an important factor to consider. After considering trade patterns over many years, Richardson initially and optimistically notes that falling trade from 1929-33 was associated with a consistent high value of the instability coefficient, signaling danger (Richardson, 1960: 225). Nevertheless, Richardson is skeptical about the magnitude of the impact of trade (cooperation) on the negative consequences of arms races, concluding that '.. . to quell the subsequent arms race by reducing the instability coefficient to zero would have required, if proportional, an increase in international trade two and a half times more rapid than the exceptional fall' (Richardson, 1960: 225).

From today's research standards, it is easy to critique Richardson's empirical analyses. Obviously, he had a tendency to select on the dependent variable, primarily focusing on expenditures before wars, and in particular the two world wars; his analysis also looked principally at subsequent participants in those wars rather than giving equal attention to those that stayed out. Subsequent empirical research does a better job of this in that it includes a number of 'no war' as well as 'no arms race' cases. It also expands the empirical domain away from the world wars, although to give Richardson credit, he does a careful examination of the 19th century as well. Given Richardson's death in 1953, he was unable to examine the impact of nuclear weapons on arms races and the outbreak of war. At least one set of findings suggests that these might be a factor that mitigates any instability that arms races produce (Sample, 2012).

Richardson is to be commended for factoring in the power distribution and cooperation (trade) into his assessment about the dangers of arms races; defense burdens are also given consideration. The best subsequent research, specifically the 'steps to war' model (Senese \& Vasquez, 2008), has also developed a multivariate and interactive approach. That work has also looked at defense burdens and power distribution gaps, but considered territorial disputes as well (see also Sample, 2012). That some arms races are dangerous and others not in a probabilistic fashion is consistent with Richardson's formulations, although later work is more developed theoretically. The importance of acceleration and the psychological impact of arms races, raised by Richardson, however, remain understudied. 


\section{References}

Diehl, Paul F (1983) Arms races and escalation: A closer look. Journal of Peace Research 20(3): 205-212.

Diehl, Paul F (1985) Arms races to war: Testing some empirical linkages. Sociological Quarterly 26(3): 331-349.

Goertz, Gary; Bradford Jones \& Paul F Diehl (2005) Maintenance processes in international rivalries. Journal of Conflict Resolution 49(5): 742-769.

Houweling, Henk W \& Jan Geert Siccama (1981) The arms race-war relationship: Why serious disputes matter. Arms Control 2(2): 157-197.

Huntington, Samuel P (1958) Arms races: Prerequisites and results. Public Policy 8(1): 41-86.

Jervis, Robert (1978a) Cooperation under the security dilemma. World Politics 30(2): 167-174.

Jervis, Robert (1978b) Perception and Misperception in International Politics. Princeton, NJ: Princeton University Press.

Kydd, Andrew (2000) Arms races and arms control: Modeling the hawk perspective. American Journal of Political Science 44(2): 228-244.

Leeds, Brett Ashley (2003) Alliance reliability in times of war: Explaining state decisions to violate treaties. International Organization 57(4): 801-827.

Ray, James Lee (1990) Friends as foes: International conflict and wars between formal allies. In: Charles Gochman \& Alan Ned Sabrosky (eds) Prisoners of War: Nation-States in the Modern Era. Lexington, KY: Lexington Books, 73-91.

Richardson, Lewis Fry (1948) War moods: I. Psychometrika 13(1): 147-174.

Richardson, Lewis Fry (1960) Arms and Insecurity: A Mathematical Study of the Causes and Origins of War. Pittsburgh, PA: Boxwood.

Rider, Toby; Michael Findley \& Paul F Diehl (2011) Just part of the game?: Arms races, rivalry, and war. Journal of Peace Research, 48(1): 85-100.

Sample, Susan (2012) Arms Races: A cause or a symptom? In: John Vasquez (ed) What Do We Know about War? Lanham. MD: Rowman \& Littlefield, 111-138.

Schneider, Gerald (2010) Economics and conflict: Moving beyond conjectures and correlations. In: Robert Denemark (ed) International Studies Encyclopedia. London: Wiley-Blackwell.

Senese, Paul \& John Vasquez (2008) The Steps to War: An Empirical Study. Princeton, NJ: Princeton University Press.

Smith, Ron P (2020) The influence of the Richardson arms race model. Ch. 3 in this volume.

Wallace, Michael D (1979) Arms races and escalation: Some new evidence. Journal of Conflict Resolution 23(1): 3-16.

Zinnes, Dina (1980) Three puzzles in search of a researcher. International Studies Quarterly 24(3): 315-342.

Paul F. Diehl, b. 1958, Ph.D. in Political Science (University of Michigan, 1983); Ashbel Smith Professor of Political Science, Associate Provost, and Director, Center for Teaching and Learning, University of Texas at Dallas (2015- ); most recent book The Puzzle of Peace: The Evolution of Peace in the International System, with Gary Goertz and Alexandru Balas (Oxford University Press, 2016), pdiehl@utdallas.edu. 
Open Access This chapter is licensed under the terms of the Creative Commons Attribution 4.0 International License (http://creativecommons.org/licenses/by/4.0/), which permits use, sharing, adaptation, distribution and reproduction in any medium or format, as long as you give appropriate credit to the original author(s) and the source, provide a link to the Creative Commons license and indicate if changes were made.

The images or other third party material in this chapter are included in the chapter's Creative Commons license, unless indicated otherwise in a credit line to the material. If material is not included in the chapter's Creative Commons license and your intended use is not permitted by statutory regulation or exceeds the permitted use, you will need to obtain permission directly from the copyright holder.

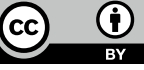

